\title{
Erectile dysfunction and associated factors among diabetic patients at, Hawassa, Southern, Ethiopia
}

\author{
Maradona Zeleke ${ }^{1}$, Dejene Hailu ${ }^{1}$ and Deresse Daka ${ }^{2 *}$
}

\begin{abstract}
Background: Erectile dysfunction is an inability to initiate and have a persistent erection firm enough to have satisfying sexual intercourse. The prevalence of erectile dysfunction in diabetic men is considerably high, but it is often underdiagnosed and under-managed.

Objective: This study aimed to determine erectile dysfunction and associated factors among diabetic patients at, Hawassa, Southern, Ethiopia.

Methods: The institution-based cross-sectional study was conducted on 352 adult male diabetic patients randomly selected from Adare general and Hawassa comprehensive specialized hospitals using a simple random sampling technique. The number of patients to be selected from each hospital was proportionally assigned based on the total population of diabetes mellitus patients following chronic care during the study period. The descriptive statistics and multiple logistic regressions (bivariate and multivariate analysis) were carried out.

Result: The prevalence of erectile dysfunction was $72.2 \%$ (95\%Cl, 1.76-3.68). After adjusting all factors, old age, diabetes duration, drinking alcohol, and poor glycemic control had shown significant association with erectile dysfunction.

Conclusion: The occurrence of erectile dysfunction in this study community is very high. Drinking alcohol, poor glycemic control, age, and duration of diabetes were predictors of erectile dysfunction in this study area. Assessment and management of erectile dysfunction in the diabetic clinic should be part of routine medical care during follow-up visits with diabetic patients. Healthcare providers should emphasize screening and treating older patients and those who have had a diabetes diagnosis for a longer duration.
\end{abstract}

Keywords: Erectile dysfunction, Diabetes mellitus, Prevalence, Associated factors, Hawassa

\section{Background}

According to the national institute of health statement of consensus, erectile dysfunction is defined as an inability to achieve or maintain an erection sufficient for satisfactory sexual performance [1]. The increasing prevalence of chronic conditions, such as Diabetes

\footnotetext{
* Correspondence: drsdk200@gmail.com

${ }^{2}$ Faculty of Medicine, Hawassa University College of Medicine and Health Sciences, Hawassa, Ethiopia

Full list of author information is available at the end of the article
}

mellitus (DM), chronic complications such as erectile dysfunction (ED) rapidly rising [2]. There has been an increase in the prevalence of ED in the general population, especially among diabetic patients [3, 4].

Some studies have shown that the impact of erectile dysfunction among men is both psychological and social effects such as lose of confidence in lifestyle, anxiety, depression, lose of a personal relationship, marked effects on their self-esteem, and lose of social and work activity [5]. 
Erectile Dysfunction (ED) is one of the major social problems causing significant distress in men. Despite the increasing difficulty in management, knowledge and understanding of factors responsible for its development are important for prevention, and care. Also, Erectile Dysfunction impairs the quality of life and is associated with depression, increased anxiety, and poor self-esteem in affected patients [6].

In 2025 about 322 million men will be affected by ED [4]. The prevalence estimates of ED in cross-sectional studies of diabetic populations range from 35 to $71 \%$ this year $[4,7]$.

As a study conducted in the USA, erectile dysfunction was $18.4 \%$ of the male population aged 20 years or older. However, the crude prevalence of erectile dysfunction was over 50\% among men with diabetes [8]. In the study conducted in Israeli, the prevalence of ED was 57\% [9], in china $90.9 \%$ [10], in India approaching $50 \%$ in both type 1 and type 2 DM [11], in Vietnam 66.9\% [12], in Brazil 66.19\% [13] and Iran 59.5\% of type 2 DM patients [14]. According to the studies done in African countries the prevalence of ED was $71.1 \%$ in Nigeria [15], $48 \%$ in Guinea [16], 85.7\% in Egypt [17], 95\% in South Africa [18], 68.8\% in Kenya [19], 74.1\% in Ivory Coast [20], 74\% in Nigeria [21], 73.9\% in Zimbabwe [22], 94.7\% in Nigeria, 36.0\% in South Africa [23], 55.1\% in Tanzania with $12.8 \%$ of participants suffering from mild dysfunction, $11.5 \%$ from moderate, and $27.9 \%$ from severe Dysfunction [3], and $69.9 \%$ Tigray Ethiopia with $32.9 \%$ suffering from mild, $31.7 \%$ moderate, and $5.2 \%$ severe erectile dysfunction [2].

The pooled prevalence of ED among patients with diabetes in Ethiopia was 54.3\% [24] with $69.9 \%$ in the Tigray region [25], 53.1\% [26], and $85.5 \%$ in the Amhara region [27], 53.3\% [28] and 60.4\% [29] in Oromia region of Ethiopia.

The magnitude of erectile dysfunction is usually underestimated in many developing countries because of several reasons. Firstly, ED is not a life-threatening condition, thus not reported. The second is associated with stigma attached to the problem, men with the problem rarely seeking help. There is also the problem of early detection and management of factors responsible for the development of erectile dysfunction [30].

Socio-demographic factors such as Age [2, 31, 32], Occupation, Monthly income [2, 31, 33], educational status $[8,13]$, Marital status [33, 34], and residence [30] are major factors in ED among DM patients. Moreover, Clinical Factors such as Duration of diabetes [3, 15, 35, 36], testosterone deficiency, peripheral neuropathy, peripheral vascular disease [4], Body mass index (BMI) [33, 37], Fasting blood glucose level (FBG) [14, 31, 36], Type of DM [9], Hypertension [15, 30] and Type of antidiabetic drugs [15], also the determinant factors of ED among DM patients. Also Behavioral or lifestyle factors such as Smoking [31, 37], not involved in physical exercise $[4,8,33]$, Alcohol drinking [12, 13] and Adherence to the drug [15] is the factors that affect ED among DM patients. Therefore, this study was aimed to determine the prevalence and associated factors of ED among diabetic patients at Hawassa teaching referral hospital and Adare General Hospital in Hawassa city. There are a few reports about the ED in Ethiopia; however, there is no related study in this study area.

\section{Methods}

\section{Study area and study period}

The study was carried out in Hawassa city administration which is the capital of SNNPR and located $275 \mathrm{~km}$ south of Addis Ababa, the capital city of Ethiopia. In Hawassa city 369,908 peoples are living according to the city's Health Department Estimation for 2017. The city structured by7 urban sub-cities collectively have 21 kebeles and 1 rural sub-city includes 11 kebeles. The city has 83 both public and private health institutions, one Public Referral and Teaching hospital, one Public General Hospital, 4 Private Primary Hospitals, 9 Public Health Centers, 17 Public Health Posts, and 53 Private Clinics. This study was conducted at Adare general and Hawassa University's comprehensive specialized hospital from January 1 to 30, 2018.

\section{Study design}

A hospital based cross-sectional study was conducted on 356 male diabetic patients attending two hospitals in the Hawassa City, Ethiopia.

\section{Source and study population Source population}

The source population constitutes all diabetic patients who are attending Adare general hospital and Hawassa comprehensive specialized hospital during the study period.

\section{Study population}

Randomly selected diabetic patients who are attending hospitals and fulfill inclusion criteria in the selected hospitals were the study population.

\section{Study unit}

All diabetic patients who are complaining of erectile dysfunction during the study period.

\section{Inclusion criteria}

Adult male patients age $\geq 18$ years with a diagnosis of DM was included. 


\section{Exclusion criteria}

Study participants with known secondary ED from genetic, endocrine, neurological, or surgical cause's patients who are severely ill and with neurocognitive impairments were excluded.

\section{Sample size determination}

The sample size was calculated by Epi info version 7 and using a confidence level of 95\%; Marginal error of 0.05; $p=0.669$ : the estimated proportion of patients with ED, as reported by a study conducted in Tigray [2]; $\mathrm{z}=$ the cut off value of the Normal distribution and; $d=$ the precision required on either side of the proportion

$$
\begin{aligned}
& \frac{Z_{\left(1-\frac{\alpha}{2}\right)}{ }^{2} * p(1-p)}{d^{2}} \\
& n=\frac{1.96^{2} * 0.699(1-0.699)}{0.05^{2}}=324
\end{aligned}
$$

Considering a non-response rate and non-willingness, $10 \%$ of the sample size 32 is added to the total sample size. The estimated sample size was 356 diabetic patients.

\section{Sampling procedures}

Two public Hospitals with chronic care services in Hawassa city, (Hawassa University comprehensive specialized hospital and Adare general hospital) both are selected purposively. Study subjects were selected from each hospital, based on proportionality and samples from each hospital were taken by using a simple random sampling technique.

\section{Data collection instrument}

Data on the prevalence and associated factors for erectile dysfunction among DM patients was collected by using an interviewer-administered questionnaire. Blood pressure and fasting blood sugar values measured for regular follow up services were obtained from patients chart. To assess the level of erectile dysfunction nationally validated standard questionnaire of 5 items international index of erectile function (IIEF5) test was used. The possible scores for the IIEF- 5 range from 1 to 25 (one question has scores of 1-5). Patients with a score of $\geq 22$ were considered to have normal erectile function and subjects with a score of $<22$ were considered to have erectile dysfunction $(\leq 7$ severe erectile dysfunction; 811moderate; $12-16$ mild-to-moderate; $17-21$ mild) [38].

\section{Data quality assurance}

The data were checked for completeness, accuracy, and clarity. The quality of the data was maintained by crosschecking daily and entering, coded, and cleaned in Epi-
Info version 7, a statistical software package then transported to SPSS windows version 20 . The quality of data was maintained by recruiting 2 facilitators and 2 data collectors who had taken training for 2 days before data collection on how to approach study subjects using the pretested questionnaire. The data collection tool was evaluated by experts and pre-tested on 10\% (34 participants) of total study participants 1 week before data collection for the consistency of understanding and completeness. During the data collection, data collectors were intensively supervised at each site. The collected data was checked out for completeness, accuracy, and clarity by investigators. This quality checking was done daily after data collection and amendments were made before the next data collection measure. Data clean-up and cross-checking were done before analysis.

\section{Data management and analysis}

After coding, the data was entered using EPI INFO version 7 , and it was exported and analyzed by using SPSS version 20 . The descriptive statistic and multiple logistic regressions were carried out to compute the relevant association. The variable with a $P$-value $<0.25$ in the bivariate analysis was entered into a multivariate logistic regression model. Significant and independently associated with dependent variables were computed and variables having $p$-value $<0.05$ in the multivariate regression model were considered at a $95 \%$ confidence interval.

\section{Result}

\section{Socio-demographic characteristics}

From 356 study participants, 352 diabetic patients were interviewed to achieve the study aim with a $98.9 \%$ response rate. The mean age of study participants was 49.14 $(+\mathrm{SD}=13.047)$ years (range: $18-90$ years) and the mean age $((+\mathrm{SD})$ for the T1DM patients was $24.8((+8.2)$ years. The mean duration of a DM diagnosis was 6.10 years $\quad(\mathrm{SD}=4.39) \quad$ (range: $1-24$ years). The majority $311(88.4 \%)$ were married and the educational status of the study participants was $31,29.8,18.8,12.5$, and $8 \%$ for college and above, high school, primary school, read and write and have no formal education respectively.

Most participants were government employees $125(35.5 \%)$, followed by merchants $78(22.2 \%)$ and a majority of the participants $274(77.8 \%)$ were from the urban and $78(22.2 \%)$ were rural residents. The mean monthly income of participants was $2003.91+1269.7$ SD Ethiopian Birr and 19(5.4\%) of participants were below 500 ETB (Table 1).

\section{Behavioral and clinical characteristics of participants}

In this study, the alcohol consumption rate, smoking cigarette, not engaging regular exercise were 16.2, 5.7, and $71 \%$, respectively. The mean FBS level of this study 
Table 1 Socio-demographic characteristics of participants of diabetic patients, at HUCSH and Adare General Hospital in Hawassa city southern Ethiopia 2018 $(n=352)$

\begin{tabular}{|c|c|c|}
\hline Characteristics & Frequency & Percent (\%) \\
\hline \multicolumn{3}{|l|}{ Educational status } \\
\hline No formal education & 28 & 8 \\
\hline Read and write & 45 & 12.78 \\
\hline Primary school & 65 & 18.75 \\
\hline High school & 105 & 29.8 \\
\hline College and above & 109 & 30.96 \\
\hline \multicolumn{3}{|l|}{ Age } \\
\hline $18-25$ & 18 & 5.1 \\
\hline $26-35$ & 35 & 9.9 \\
\hline $36-45$ & 90 & 25.6 \\
\hline $46-55$ & 102 & 29 \\
\hline$>55$ & 107 & 30.4 \\
\hline \multicolumn{3}{|l|}{ Occupation } \\
\hline Unemployed & 48 & 13.6 \\
\hline Daily labor & 5 & 1.4 \\
\hline Merchant & 78 & 22.2 \\
\hline Government employee & 125 & 35.5 \\
\hline Private/NGO & 43 & 12.5 \\
\hline Farmer & 53 & 15.1 \\
\hline \multicolumn{3}{|l|}{ Marital status } \\
\hline Single & 25 & 7.1 \\
\hline Married & 311 & 88.4 \\
\hline Divorced & 10 & 2.8 \\
\hline Widowed & 6 & 1.7 \\
\hline \multicolumn{3}{|l|}{ Residence } \\
\hline Rural & 274 & 77.8 \\
\hline Urban & 78 & 22.2 \\
\hline \multicolumn{3}{|c|}{ Monthly income in Eth. birr ${ }^{a}$} \\
\hline$<500$ & 19 & 5.4 \\
\hline $501-1500$ & 138 & 39.2 \\
\hline $1501-2500$ & 90 & 25.6 \\
\hline $2501-3500$ & 67 & 19 \\
\hline
\end{tabular}

participants were $116.5 \mathrm{mg} / \mathrm{dl}$, with $69 \%(n=243)$ of participants are in the normal range $(<126 \mathrm{mg} / \mathrm{dl})$ and $31 \%(n=109)$ of participants above the normal range $(\geq 126 \mathrm{mg} / \mathrm{dl})$. About $93.5 \%(n=329)$ had type II DM, and only $6.5 \%(n=23)$ had Type I DM. The mean BMI of respondents was $22.75 \mathrm{Kg} / \mathrm{m}^{2}$, while it was $19.275 \mathrm{Kg} / \mathrm{m}^{2}$ for T1DM patients. About $72.4 \%$ $(n=255)$ of study participants were in normal range $\left(\mathrm{BMI}=18.5-24.9 \mathrm{Kg} / \mathrm{m}^{2}\right)$ and $27.6 \% \quad(n=97)$ were overweight $\left(\mathrm{BMI}=25-29.9 \mathrm{Kg} / \mathrm{m}^{2}\right)$.
Table 2 Lifestyle, behavioral and clinical characteristics of participants of diabetic patients at Hawassa city, SNNPR Ethiopia, $2018(n=352)$

\begin{tabular}{lll}
\hline Variables & Frequency & Pe \\
\hline Alcohol drinking & & \\
Yes & 57 & 16.2 \\
No & 295 & 83.8 \\
Smoking cigar ate & & \\
Yes & 20 & 5.7 \\
No & 332 & 94.
\end{tabular}

Physical exercise

Yes

102

No

250

Drug adherence

Yes

312

No

ercent

Fasting blood glucose

$<126$

39.8

$\geq 126$

Type of DM

Type I

6.5

Type II

93.5

BMI

Underweight 0

0

Normal

60.8

Overweight

39.2

Obese

0

BP

Normal

30.1

Elevated

8.6

Stage1 HTN

31.5

Stage2 HTN

29.8

Type of hypoglycemic drug

Oral

Injectable

Duration of diabetes

$<5$ yrs

29.5

5-10 yrs

37.5

$>10$ yrs

32.9

Erectile dysfunction

Yes

72.2

No

Category of ED $(n=254)$

Mild

Moderate

Severe

3.9 


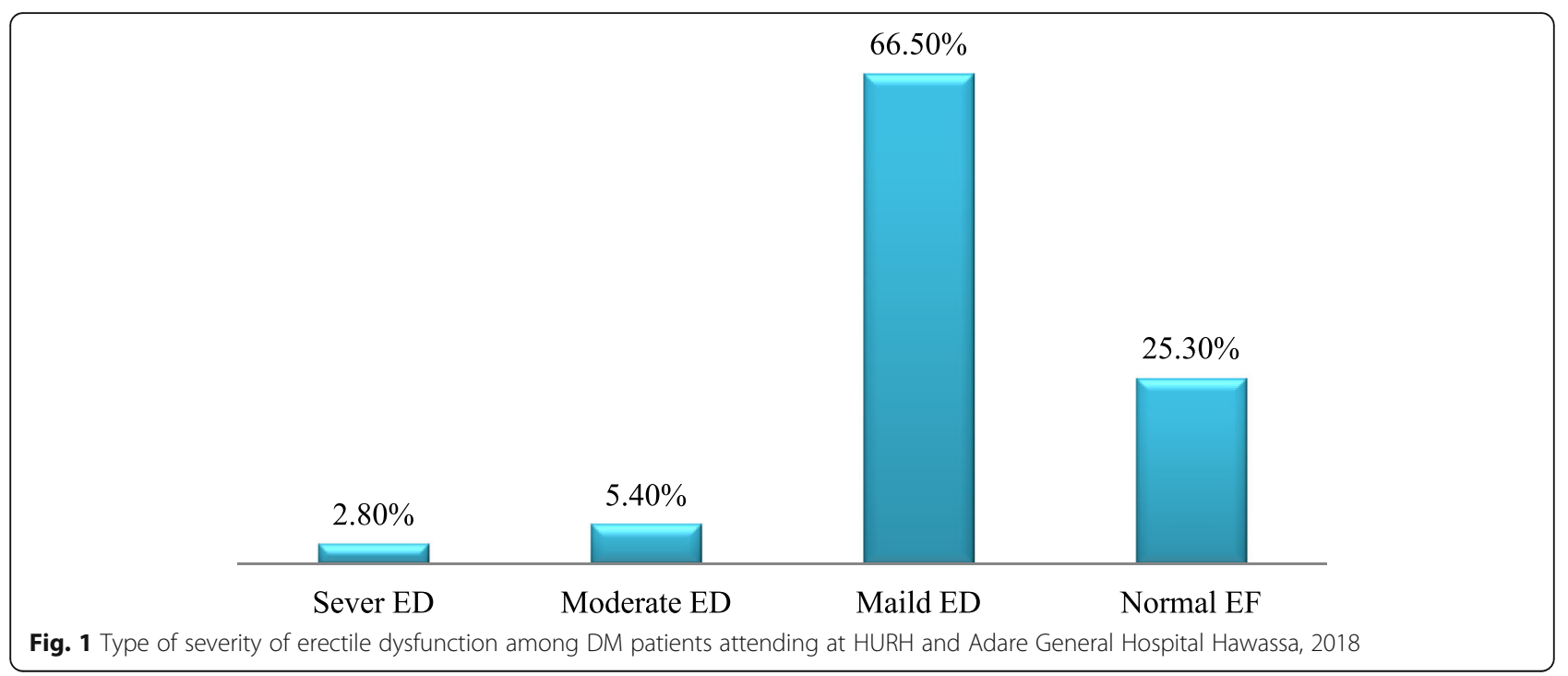

Also, blood pressure and fasting blood glucose were obtained from the record of the DM patients. Nearly half of (48.3\%) the participants were within the normal range for blood pressure ( $\mathrm{BP}<120 / 80 \mathrm{mmHg}$ ), $24 \%$ of the participants had elevated blood pressure (BP $>120-129 / 80$ $\mathrm{mmHg}$ ) while the rest of the participants had either Stage $1(13.9 \%)$ or Stage $2(13.1 \%)$ hypertension. The majority of participants (60.8\%) were on oral hypoglycemic medication and while others (39.2) were using injectable medication. Three hundred and twelve $(88.6 \%)$ participants were adherent to the DM drug (Table 2).

\section{Prevalence of ED}

The prevalence of ED in this study was $72.2 \%$ of which 252(88.6\%) had mild ED, 19(7.5\%) had moderate ED and 10(3.9\%) had severe ED. Only $27.8 \%$ of the patients had normal erectile function Fig. 1.

\section{Factors associated with ED}

The bivariate logistic analysis of socio demographic characteristics with ED revealed that all sociodemographic characteristics, age $(\mathrm{AOR}=3.2,95 \% \mathrm{CI}=$ $1.32-4.34, \quad p=0.04)$, Alcohol $(\mathrm{AOR}=3.23,95 \% \mathrm{CI}=$ $1.03-10.44, p=0.049)$, FBS (AOR $=10.3,95 \% \mathrm{CI}=3.92-$ 27.44, $p=0.00$ ) and Diabetic duration (AOR $=17.7$, $95 \% \mathrm{CI}=6.57-48.01, \quad p=0.001) \quad$ showed a significant association.

In the multivariate analysis, the odds of having erectile dysfunction among diabetic patients having an age group of above 55 years was 3.2 times $[\mathrm{AOR}=3.2,95 \% \mathrm{CI}=$ 1.32-4.34, $p=0.04)$ ] more likely developing erectile dysfunction compared to age less than 25 years. The odds of having erectile dysfunction with a duration of diabetes $>10$ years increased the risk of having erectile dysfunction $\quad[\mathrm{AOR}=17.7, \quad 95 \% \mathrm{CI}=6.87-48.01, \quad p=$ $0.001)$ ] compared with diabetes duration of $<5$ years and the diabetic duration of $5-10$ years increase the risk by $2.66(\mathrm{AOR}=2.66,95 \% \mathrm{CI}, 1.13-6.27, p=0.025)$ as compared with the age less than 5 years. The likelihood of erectile dysfunction among respondents who drink alcohol was increased by 3.23 times $[\mathrm{AOR}=3.23,95 \% \mathrm{CI}$ : $1.03-10.44, p=0.049)]$ as compared to their counterparts. The risk of developing erectile dysfunction among diabetics with poor glycemic control (FBS $>126 \mathrm{mg} / \mathrm{dl}$ ) was increased by 10.3 times $(\mathrm{AOR}=10.3,95 \% \mathrm{CI}, 3.92$ 27.44, $p=0.000)$ as compared with $\mathrm{FBS}<126 \mathrm{mg} / \mathrm{dl}$ (Table 3).

\section{Discussion}

In this study, the prevalence of ED among diabetic patients was 254(72.2\%). This is in line with studies conducted in different parts of the world ranging between 35 and $90 \%$. Moreover, the study finding coincides with the results from Nigeria, $71.1 \%$ [15] and the Tigray region of Ethiopia, 69.9\% [2]. Also, the study conducted in Iran and Saudi Arabia showed that the prevalence of ED was $77 \%$ [14] and $80-90 \%$ [36] respectively. However, there is some discrepancy with the study conducted in Tanzania, Nigeria, Iran, Jordan, and Israel which is 55 , $58,59.5,62$, and $67 \%$, respectively $[2,9,32,36]$. The possible reason may be attributed to differences in the socio-cultural context of study participants, study design, and sample size.

Factors associated with erectile dysfunction are age above 55 years, duration of diabetes of above 10 years, drinking alcohol, and fasting blood glucose level $>126$ $\mathrm{mg} / \mathrm{dl}$. Most studies have similar results demonstrating age and duration of diabetes, poor glycemic control, and 
Table 3 Bivariate and multivariate logistic regression of ED with predictor variables among diabetic patients in Hawassa city, Jan 2018

\begin{tabular}{|c|c|c|c|c|c|}
\hline \multirow[t]{2}{*}{ Variable } & \multicolumn{2}{|c|}{ Erectile Dysfunction } & \multirow[t]{2}{*}{$\operatorname{COR}(95 \% \mathrm{Cl})$} & \multirow[t]{2}{*}{ AOR $(95 \% \mathrm{Cl}$} & \multirow{2}{*}{$\begin{array}{l}p \\
\text { value }\end{array}$} \\
\hline & Yes & No & & & \\
\hline \multicolumn{6}{|l|}{ Age } \\
\hline $15-25$ & 3 & 15 & 1 & 1 & \\
\hline $26-35$ & 16 & 19 & $0.04(0.001-0.023)$ & $0.238(0.026-2.168)$ & 0.04 \\
\hline $36-45$ & 46 & 44 & $0.002(0.006-0.082)$ & $0.274(0.026-2.84)$ & \\
\hline $45-55$ & 84 & 18 & $0.029(0.009-0.098)$ & $0.77(0.072-8.26)$ & \\
\hline$>55$ & 105 & 2 & $2.42(1.73-3.83)$ & $3.2(1.32-4.34)^{*}$ & \\
\hline \multicolumn{6}{|l|}{ Occupation } \\
\hline Unemployed & 38 & 10 & 1 & 1 & \\
\hline Daily labor & 1 & 4 & $0.27(0.13-0.69)$ & $1.57(0.095-26.05)$ & $>0.05$ \\
\hline Merchant & 62 & 16 & $1.02(0.42-2.47)$ & $3.06(0.299-31.33)$ & \\
\hline Gov. employee & 78 & 47 & $0.437(0.199-0.957)$ & $1.03(0.91-11.75)$ & \\
\hline Private/NGO & 26 & 17 & $0.402(0.159-1.017)$ & $0.76(0.071-8.26)$ & \\
\hline Farmer & 49 & 4 & $1.287(0.473-3.496)$ & $0.6(0.04-9.01)$ & \\
\hline \multicolumn{6}{|l|}{ Marital status } \\
\hline Single & 6 & 19 & 1 & 1 & \\
\hline Married & 233 & 74 & $3.5(1.5-8)$ & $7.3(0.937-56.84)$ & $>0.05$ \\
\hline Divorced & 7 & 3 & $6(1.21-29.72)$ & $11.13(6.22-67.25)$ & \\
\hline Widowed & 8 & 2 & $4.23(2.27-6.32)$ & $1.63(0.952-5.54)$ & \\
\hline \multicolumn{6}{|l|}{ Educational status } \\
\hline No formal education & 25 & 3 & 1 & 1 & \\
\hline Read and write & 43 & 2 & $2.3(0.48-11.31)$ & $5.66(0.587-54.84)$ & $>0.05$ \\
\hline Primary school & 51 & 14 & $0.556(0.166-1.855)$ & $1.14(0.155-8.46)$ & \\
\hline High school & 70 & 35 & $0.32(0.103-0.991)$ & $1.57(0.196-12.71)$ & \\
\hline College and above & 65 & 44 & $0.215(0.061-0.76)$ & $3.37(0.346-32.98)$ & \\
\hline \multicolumn{6}{|c|}{ Monthly income (Eth.Birr) } \\
\hline$<500$ birr & 15 & 4 & 1 & 1 & \\
\hline 500-1500 birr & 114 & 24 & $1.6(0.53-4.89)$ & $0.71(0.097-5.32)$ & $>0.05$ \\
\hline 1501-2500 birr & 58 & 32 & $0.21(0.045-0.99)$ & $0.21(0.025-1.86)$ & \\
\hline 2501-3500 birr & 42 & 25 & $0.56(0.18-1.75)$ & $0.29(0.032-2.64)$ & \\
\hline$>3500$ birr & 25 & 13 & $0.612(0.82-2.06)$ & $0.30(0.03-3.03)$ & \\
\hline \multicolumn{6}{|l|}{ Residence } \\
\hline Urban & 192 & 83 & 1 & 1 & \\
\hline Rural & 62 & 15 & $1.92(1-3.69)$ & $1.91(0.67-5.5)$ & $>0.05$ \\
\hline \multicolumn{6}{|l|}{ Alcohol } \\
\hline Yes & 51 & 6 & $0.24(0.093-0.626)$ & $3.23(1.03-10.44)^{*}$ & 0.049 \\
\hline No & 203 & 92 & 1 & 1 & \\
\hline \multicolumn{6}{|l|}{ Smoking } \\
\hline Yes & 15 & 5 & $1.19(0.42-3.37)$ & & \\
\hline No & 239 & 93 & 1 & 1 & $>0.05$ \\
\hline \multicolumn{6}{|l|}{ Physical exercise } \\
\hline Yes & 44 & 58 & $0.167(0.099-0.282)$ & $0.49(0.23-1.09)$ & \\
\hline No & 210 & 40 & 1 & 1 & $>0.05$ \\
\hline
\end{tabular}


Table 3 Bivariate and multivariate logistic regression of ED with predictor variables among diabetic patients in Hawassa city, Jan 2018 (Continued)

\begin{tabular}{|c|c|c|c|c|c|}
\hline \multirow[t]{2}{*}{ Variable } & \multicolumn{2}{|c|}{ Erectile Dysfunction } & \multirow[t]{2}{*}{ COR(95\%Cl) } & \multirow[t]{2}{*}{ AOR(95\%Cl } & \multirow{2}{*}{$\begin{array}{l}p \\
\text { value }\end{array}$} \\
\hline & Yes & No & & & \\
\hline \multicolumn{6}{|l|}{ Adherence } \\
\hline Yes & 223 & 89 & $0.785(0.369-1.67)$ & & \\
\hline No & 31 & 9 & 1 & 1 & $>0.05$ \\
\hline \multicolumn{6}{|l|}{ Type of DM } \\
\hline Type 1 & 9 & 14 & 1 & 1 & \\
\hline Type 2 & 245 & 84 & $5.1(2.1-12.5)$ & $1.49(0.22-10.06)$ & $>0.05$ \\
\hline \multicolumn{6}{|c|}{ Type of hypoglycemic drug } \\
\hline Oral & 133 & 81 & 1 & 1 & \\
\hline Injectable & 121 & 17 & $4.04(2.3-7.06)$ & $5.05(1.15-11.23)$ & $>0.05$ \\
\hline \multicolumn{6}{|l|}{ FBS } \\
\hline$<126$ & 67 & 73 & 1 & 1 & \\
\hline$>126$ & 187 & 25 & $8.1(4.78-13.89)$ & $10.3(3.92-27.44)^{* *}$ & 0.000 \\
\hline BP & & & 1 & & \\
\hline Normal & 35 & 71 & 4.06(1.725-9.59) & $2.15(0.576-8.07)$ & \\
\hline Elevated & 20 & 10 & $14.5(7.15-29.4)$ & $0.80(0.348-1.83)$ & $>0.05$ \\
\hline Stage1 HTN & 98 & 13 & $15.3(7.55-30.98)$ & $1.49(0.42-5.29)$ & \\
\hline Stage2 HTN & 101 & 4 & $51.2(17.43-150.54)$ & 1 & \\
\hline \multicolumn{6}{|l|}{ BMI } \\
\hline Underweight & 0 & 0 & & & \\
\hline Normal & 128 & 86 & 1 & 1 & \\
\hline Overweight & 126 & 12 & 7.05(0.635-1.82) & & $>0.05$ \\
\hline Obese & 0 & 0 & & & \\
\hline \multicolumn{6}{|c|}{ Diabetic duration } \\
\hline$<5$ yrs. & 45 & 59 & 1 & 1 & \\
\hline $5-10$ yrs. & 102 & 30 & $4.45(2.54-7.82)$ & $2.66(1.13-6.27)^{*}$ & 0.025 \\
\hline$>10 \mathrm{yrs}$ & 107 & 9 & 15.5(7.11-34.1) & $17.7(6.57-48.01)^{* *}$ & 0.001 \\
\hline
\end{tabular}

* Significant at $p$-value $<0.05$. ** Significant at $p$-value $<0.001$

drinking alcohol are significantly associated with ED [2, $13,15,30]$.

This study showed that older age was 3.2 times more likely to develop ED than a younger one. This is similar to the study conducted by Mebrahtu Abay [2], Mohamed AK et al. [39], Giuliano FA et al. [40], Martin. $\mathrm{M}$ et al. [41], Khatib F et al. [36]. This might be due to age-related physiological changes in the testicles and a decline in male sex hormones have been attributed to the increasing incidence of ED in older men.

In this study, individual engagement in an unhealthy lifestyle and behavior like drinking alcohol showed that erectile dysfunction was positively associated among DM patents. The risk is increased by 3.23 [AOR $=3.2$, $95 \% \mathrm{CI}=1.03-10.44, p=0.049]$ times more as a determinant factor compared with those who don't drink alcohol. This result is similar to the study conducted in
India and Brazil [11, 13]. Also, other researchers have presented similar results regarding alcohol as a determinant factor for ED [42-44]. Even though a few facts were evaluated in most of the studies done in other parts of the world about alcohol factors, the possible explanation might be due to alcohol abuse causing irreversible damage to nerve endings in the penis tissue. Alcohol is a depressant, and its frequent use decrease sexual desire, and make it difficult for a man to achieve erections or reach an orgasm while under the influence of alcohol. In fact, overdoing it on booze is a common cause of erectile dysfunction Moreover, intoxication can slow down or interrupt those signals between the brain and body, resulting in ED. [45]. Also, alcohol may develop stressfree lifestyles which are sedentary [45]. In this study, smoking habits did not appear as independent predictor of ED, because of low level of power of the test (64.22). 
Persistently elevated blood glucose is also another statistically associated variable with erectile dysfunction in this study. This finding is consistent with the study conducted in Jordan [36] and Nigeria [15]. In this study, the risk of having ED among diabetic patients was increased by 10.3 times as compared to good glycemic controlled patients. The possible explanation for this could be poor glycemic control which is associated with nearly all microvascular complications in DM patients.

In this study, the longer duration of diabetes is significantly associated with erectile dysfunction in multivariate analysis. The risk is $17.7(\mathrm{CI}, 6.57-48.01)$ times higher in duration $>10$ years as compared with duration less than five. This finding is in agreement with a study from Tigray, Ethiopia, India [2, 11]. It is commonly known that many of the microvascular and macrovascular complications of DM increase with a longer duration of DM. The possible explanation of this result might be the prevalence of diabetes-related ED is mostly neurogenic and vasculogenic in etiology that increases with longer duration of DM. Moreover, as a study shown by Mohamed AK and Ahmed S, the prevalence of low testosterone was higher in patients with a longer duration of DM [39].

The average age of participants of this study is about 50 years implying that they are already at increased risk of cardiovascular diseases which could be further compounded by high prevalence of ED observed in this study. The psychosocial implication of ED will have huge impact on the quality of life of DM patients and that of their families unless it received due attention by the service providers to identify the problem at early stage and treat it.

\section{Limitations}

This study was not measured about microvascular and macrovascular complications in DM patients. Similarly, HbA1c which could have shown glycemic control in more accurate manner, and serum testosterone levels were not measured. Therefore, this study is limited to a cross-sectional study, so that another study design is needed to determine further.

\section{Conclusion}

In conclusion, the prevalence of ED among diabetic men is high. It increases with age, poor glycemic control, diabetic duration, and alcohol consumption. Assessment and management of ED should be part of routine medical care in diabetic follow-up clinics. Healthcare providers should openly ask men with chronic diseases, particularly those with diabetes, about symptoms of ED. An appropriate medication, sexual counseling is recommended. Further, a study with other variables is very important.
Abbreviations

AOR: Adjusted odds ratio; COR: Crude odds ratio

\section{Supplementary Information}

The online version contains supplementary material available at https://doi. org/10.1186/s12902-021-00807-5.

Additional file 1.

\section{Acknowledgments}

The authors would like to thank Hawassa University, College of Medicine and Health Sciences, and study participants.

\section{Authors' contributions}

$M Z$ : wrote the proposal, participated in data collection, analyzed the data, and drafted the paper. DD: participated in the design, and acquisition of data, analysis, and interpretation of data. DH: read the manuscript and finalized the analysis and conception, design, analysis, and interpretation of data. All authors read and approved the final manuscript.

\section{Funding}

This study was supported by Hawassa University, College of Medicine and Health Sciences, and Sothern region health bureau. The support included payment for data collectors and the purchase of materials and supplies required for the study. The support did not include designing of the study, analysis, and interpretation of data, and manuscript preparation.

Availability of data and materials

The data used/analyzed during the current study available from the corresponding author on reasonable request.

\section{Declarations}

Ethics approval and consent to participate

The survey has been conducted after approved by the IRB (Institutional Review Board) of Hawassa University College of Medicine and Health Sciences. Verbal informed consent was obtained from all participants who were $>=16$ years old. For those less than 16 years old, an assent was obtained and verbal consent was sought from their parent. The purpose of the study and the confidential nature of the study were discussed with each participant. The information provided by each respondent was kept confidential and anonymously analyzed. Official permission letter was obtained from Hawassa City Health Department to conduct the study.

Consent for publication

Not applicable.

Competing interests

The authors declare that we have no conflict of interests.

\section{Author details}

${ }^{1}$ School of Public Health, Hawassa University College of Medicine and Health Sciences, Hawassa, Ethiopia. ${ }^{2}$ Faculty of Medicine, Hawassa University College of Medicine and Health Sciences, Hawassa, Ethiopia.

Received: 12 November 2020 Accepted: 23 June 2021

Published online: 01 July 2021

References

1. Consensus NIoH. Impotence: $\mathrm{NIH}$ development panel on impotence. JAMA. 1993;270(1):83-90. https://doi.org/10.1001/jama.1993.03510010089036.

2. Abay M. Prevalence and determinants of erectile dysfunction among diabetic patients attending in hospitals of central and northwestern zone of Tigray. BMC Endocrine Disord BMC. 2017;17(16).

3. Mutagaywa RK, Lutale J, Aboud M, Kamala BA. Prevalence of erectile dysfunction and associated factors among diabetic men attending diabetic clinic at Muhimbili National Hospital in Dar-es-Salaam, Tanzania. Pan Afr Med J. 2014;17(227). https://doi.org/10.11604/pamj.2014.17.227.2695. 
4. Shiferaw WS, Akalu TY, Aynalem YA. Prevalence of erectile dysfunction in patients with diabetes mellitus and its association with body mass index and glycated hemoglobin in africa: a systematic review and meta-analysis. Int J Endocrinol. 2020;2020.

5. Tomlinson JM, Wright D. Impact of erectile dysfunction and its subsequent treatment with sildenafil: qualitative study. BMJ. 2004;328(7447):1037. https://doi.org/10.1136/bmj.38044.662176.EE.

6. Mohamed AH, Yaseen K, Ranjeev H. Assessment of knowledge and perception of erectile dysfunction among diabetic and non-diabetic patients at a university health center in Malaysia. Asian J Pharmaceut Clin Res. 2009;2(3).

7. Penson DF, Wessells H. Erectile Dysfunction in Diabetic Patients. Diabetes Spectrum. 2004;17(4):225-30.

8. Selvin E, Burnett AL, Platz EA. Prevalence and risk factors for erectile dysfunction in the US. Am J Med. 2007;120(2):151-7. https://doi.org/10.1016/ j.amjmed.2006.06.010.

9. Roth A, Kalter-Leibovici O, Kerbis Y, Tenenbaum-Koren E, Chen J, Sobol T, et al. Prevalence and risk factors for erectile dysfunction in men with diabetes, hypertension, or both diseases: a community survey among 1,412 Israeli men. Clin Cardiol. 2003;26(1):25-30. https://doi.org/10.1002/clc.4960260106.

10. Chaudhary RK, Shamsi BH, Tan T, Chen HM, Xing JP. Study of the relationship between male erectile dysfunction and type 2 diabetes mellitus/metabolic syndrome and its components. J Int Med Res. 2016;44(3): 735-41. https://doi.org/10.1177/0300060515623122.

11. Singh K, Devi S, Pankaj PP. Diabetes associated male reproductive dysfunctions: prevalence, diagnosis and risk factors. Int J Drug Dev and Res. 2016:8(2):007-10.

12. Van Vo T, Hoang HD, Thanh Nguyen NP. Prevalence and associated factors of erectile dysfunction among married men in Vietnam. Front Public Health. 2017:5:94.

13. Costa MR, Reis AM, Pereira BP, Ponciano VC, Oliveira EC. Associated factors and prevalence of erectile dysfunction in hemodialysis patients. Int Braz J Urol. 2014;40(1):44-55. https://doi.org/10.1590/S1677-5538.IBJU.2014.01.07.

14. Sharifi F, Asghari M, Jaberi Y, Salehi O, Mirzamohammadi F. Independent predictors of erectile dysfunction in type 2 diabetes mellitus: is it true what they say about risk factors? ISRN Endocrinol. 2012;2012(5).

15. Ugwu T, Ezeani I, Onung S, Kolawole B, Ikem R. Predictors of erectile dysfunction in men with type 2 diabetes mellitus referred to a tertiary healthcare centre. Adv Endocrinol. 2016;2016(8).

16. Baldé $\mathrm{NM}$, Diallo $\mathrm{AB}$, Baldé $\mathrm{MC}$, et al. Dysfonction érectile et diabète à Conakry (Guin'ee): fréquence et profil clinique à partir de 187 observations. Ann Endocrinol. 2006;67(4):338-42.

17. El Saghier EOA, Shebl SE, Fawzy OA, Eltayeb LM, Bekhet LM, Gharib A. Androgen deficiency and erectile dysfunction in patients with type 2 diabetes. Clin Med Insights: Endocrinol Diabetes. 2015;8:S27700.

18. Kemp T, Rheeder P. Prevalence and associations of erectile dysfunction in a south African male diabetic urban population journal of endocrinology. Metabol Diabetes South Afr. 2015;20(3):134-9.

19. Likata GMU, Kuria MW, Olando Y, Owiti FR. Sexual dysfunction among patients with diabetes mellitus. Greener J Med Sci. 2012;2(6):138-45. https:// doi.org/10.15580/GJMS.2012.5.110112196.

20. Lokrou A, Soumahoro SI. La dysfonction érectile chez les personnes atteintes de diabète en Côte-d'Ivoire. Médecine des Maladies Métaboliques. 2011;5(2):203-7

21. Olarinoye J, Kuranga S, Katibi I, Adediran O, Jimoh A, Sanya E. Prevalence and determinants of erectile dysfunction among people with type 2 diabetes in Ilorin, Nigeria. Niger Postgrad Med J. 2006;13(4):291-6.

22. Machingura VCPI. Erectile dysfunction among diabetic patients at parirenyatwa group of hospitals in Zimbabwe. Texila Inte J Public Health. 2018;6(2):69-73. https://doi.org/10.21522/TIJPH.2013.06.02.Art009.

23. Webb EM, Rheeder P, Van Zyl DG. Diabetes care and complications in primary care in the Tshwane district of South Africa. Prim Care Diabetes. 2015;9(2):147-54. https://doi.org/10.1016/j.pcd.2014.05.002.

24. Adisu BW, Sewnet AK, Biruk ST. Prevalence of erectile dysfunction and its associated factors among patients with diabetes in Ethiopia: a systematic review and meta-analysis. J Int Med Res. 2021:49(2):1-10.

25. Seid A, Gerensea H, Tarko S, Zenebe Y, Mezemir R. Prevalence and determinants of erectile dysfunction among diabetic patients attending in hospitals of central and northwestern zone of Tigray, northern Ethiopia: a crosssectional study. BMC Endocr Disord. 2017;17(1):16. https://doi.org/10.11 86/s12902-017-0167-5.
26. Tesfaye T, Bayisa M, Mesfin N. Prevalence and associated factors of erectile dysfunction among men DM patients in Gondar university hospital, Gondar Ethiopia. Research Square; 2020. https://doi.org/10.21203/rs.2.20496/v1.

27. Walle B, Lebeta KR, Fita YD, Abdissa HG. Prevalence of erectile dysfunction and associated factors among diabetic men attending the diabetic clinic at Felege Hiwot referral hospital, Bahir Dar, north West Ethiopia 2016. BMC Res Notes. 2018;11(1):130. https://doi.org/10.1186/s13104-018-3211-2.

28. Asefa A, Nigussie T, Henok A, et al. Prevalence of sexual dysfunction and related factors among diabetes mellitus patients in Southwest Ethiopia. BMC Endocr Disord. 2019;19(141).

29. Hurisa AD, Negera GZ. Erectile dysfunction among diabetic patients in a tertiary hospital of Southwest Ethiopia. Open Publ Health J. 2020;13(1):2405. https://doi.org/10.2174/1874944502013010240.

30. Idung AU, Abasiubong F, Ukott IA, Udoh SB, Unadike BC. Prevalence and risk factors of erectile dysfunction in Niger delta region, Nigeria. Afr Health Sci. 2012;12(2):160-5. https://doi.org/10.4314/ahs.v12i2.13.

31. Selim S, Chowdhury SH, Azad AK, Chowdhury MAJ, Rahaman FR. Frequency and risk factors of erectile dysfunction in Bangladeshi diabetic men. J Endocrinol Diabetes Obes. 2015;3(3):1075.

32. Unadike BC, Eregie A, Ohwovoviole AE. Prevalence and types of sexual dysfunction amongst males with diabetes in Nigeria. Afr J Diabetes Med. 2008;2008:18-20.

33. Adebusoye LA, Olapade-olaopa OE, Ladipo MM, Owoaje ET. Prevalence and correlates of erectile dysfunction among primary care clinic attendees in Nigeria. Global J Health Sci. 2012;4(4):107-17. https://doi.org/10.5539/gjhs.v4 n4p107.

34. Shiri R, Koskimäki J, Häkkinen J, Tammela TL, Huhtala H, Hakama M, Auvinen A; Tampere Ageing Male Urological Study. Effects of age, comorbidity and lifestyle factors on erectile function: Tampere Ageing Male Urological Study (TAMUS). Eur Urol. 2004;45(5):628-33. https://doi.org/10.1016/j.eururo.2 003.11.020.

35. Chaudhary RK, Shamsi BH, Tan T, Chen HM, Xing JP. Study of the relationship between male erectile dysfunction and type 2 diabetes mellitus/metabolic syndrome and its components. J Int Med Res. 2016;44(3): 735-41. https://doi.org/10.1177/0300060515623122.

36. Khatib FA, Jarrah NS, Shegem NS, Bateiha AM, Abu-Ali RM, Ajlouni KM. Sexual dysfunction among Jordanian men with diabetes. Saudi Med J. 2006; 27(3):351-6.

37. Culley C, Roger S, Irwin G, Michael G. Textbook of erectile dysfunction; 2009.

38. Rosen RC, Cappelleri JC, Smith MD, Lipsky J, Peña BM. Development and evaluation of an abridged, 5 -item version of the International Index of Erectile Function (IIEF-5) as a diagnostic tool for erectile dysfunction. Int J Impot Res. 1999;1 1(6):319-26. https://doi.org/10.1038/sj.ijir.3900472.

39. Mohamed AK, Sonbol A. Study of risk factors for erectile dysfunction in patients with type 2 diabetes mellitus: correlation to serum testosterone level. Elsevier, Alexandria J Med. 2018;54:319-21.

40. Giuliano FA, Leriche A, Jaudinot EO, de Gendre AS. Prevalence of erectile dysfunction among 7689 patients with diabetes or hypertension, or both. Urology. 2004;64(6):1196-201. https://doi.org/10.1016/j.urology.2004.08.059.

41. Martin-Morales A, Sanchez-Cruz JJ, Saenz de Tejada I, et al. Prevalence and independent risk factors for erectile dysfunction in Spain: results of the Epidemiologia de la Disfuncion Erectil Masculina Study. J Urol. 2001;166(2): 569-74.

42. Siu SC, Lo SK, Wong KW, Ip KM, Wong YS. Prevalence of and risk factors for erectile dysfunction in Hong Kong diabetic patients. Diabet Med. 2001;18(9): 732-8. https://doi.org/10.1046/j.0742-3071.2001.00557.x.

43. Cho NH, Ahn CW, Park JY, Ahn TY, Lee HW, Park TS, et al. Prevalence of erectile dysfunction in Korean men with type 2 diabetes mellitus. Diabet Med. 2005:23:198-203.

44. Al-Hunayan A, Al-Mutar M, Kehinde EO, Thalib L, Al-Ghorory M. The prevalence and predictors of erectile dysfunction in men with newly diagnosed with type 2 diabetes mellitus. BJU Int. 2007;99(1):130-4. https:// doi.org/10.1111/j.1464-410X.2006.06550.X.

45. Owiredu KBA, et al. Determinants of sexual dysfunction among clinically diagnosed diabetic patients. Reprod Biol Endocrinol. 2011;9(70).

\section{Publisher's Note}

Springer Nature remains neutral with regard to jurisdictional claims in published maps and institutional affiliations. 